\title{
Why is sudden infant death syndrome more common at weekends?
}

S M Williams, E A Mitchell, R Scragg, and the New Zealand National Cot Death Study Group

\begin{abstract}
Objectives-To determine whether the prevalence of known risk factors and the magnitude of their association with sudden infant death syndrome (SIDS) differed between weekends and weekdays. Method-A large nationwide case-control study, comparing interview data for 393 cases with 1591 controls.

Results-Sudden infant death syndrome occurred more often at weekends, more deaths occurring on Sunday than on any other day of the week. Significant interaction effects were found between weekends and sharing a room with an adult and the parents going to a party. After adjustment for confounders, room sharing was less protective at the weekends (odds ratio $(O R)=0.66,95 \%$ confidence interval $(C I)$ 0.43 to 1.03 ) than it was on weekdays (OR $=0.41,95 \%$ CI 0.30 to 0.57 ) using not room sharing and weekdays as the reference group. Although the likelihood of SIDS after a party was higher at weekends (OR $=2.47,95 \%$ CI 1.11 to 5.47 ) than on weekdays $(\mathrm{OR}=0.55,95 \%$ CI 0.21 to 1.37$)$, few cases were reported. Being Maori $(\mathrm{OR}=$ $3.35,95 \%$ CI 1.75 to 6.43 ) or the child of an unmarried mother $(\mathrm{OR}=3.91,95 \%$ CI 2.20 to 6.92) were risk factors for SIDS occurring on Sundays.

Conclusions-The increase in SIDS at weekends may be explained in part by the lesser protective effect of sharing a bedroom with an adult at that time. It may also be related to social activities that occur at weekends.
\end{abstract}

(Arch Dis Child 1997;77:415-419)

Keywords: SIDS; weekends; room sharing

Studies in New Zealand, ${ }_{1}^{1}$ England, ${ }^{2}$ Australia, ${ }^{3}$ Norway, ${ }^{4}$ and Scotland ${ }^{5}$ have suggested that sudden infant death syndrome (SIDS) is more common at weekends than it is on weekdays. It has been speculated that this could be the consequence of changed parental routines, changes in the environment, or the parents' reluctance to seek help for what is believed to be a trivial illness. ${ }^{16}$

We have used data from the New Zealand Cot Death Study, ${ }^{78}$ a large nationwide casecontrol study, to examine differences between infants who died on weekdays and those who died at weekends. We hypothesised that factors which might explain the excess of weekend deaths were characteristics of the family, differences in child care practices, or differences in routine in the last one or two days before death. The use of alcohol in the last month was also examined.

\section{Methods}

The New Zealand Cot Death Study was a case-control study using a sample of infants drawn from health districts in Auckland, the central North Island, southern North Island, Christchurch, and southern South Island. During the study period from 1 November 1987 to 31 October 1990, 78\% of all New Zealand live births were reported from these areas. Infants dying between the age of 28 days and 1 year (the postneonatal period) were enrolled in the study if they had a diagnosis of SIDS with or without other abnormalities. Cases were classified as SIDS by regional pathologists in consultation with a local paediatrician according to an agreed protocol. The study pathologist reviewed cases about which there was uncertainty. The protocol for the necropsies has been described in detail previously. $^{78}$

Controls were selected so that the distribution of their ages on the day about which they were interviewed (the nominated day) would be similar to the distribution of the ages at which cases were expected to die. This was done by randomly selecting days from all 365 days of the year and assigning each an age, making it possible to work backwards to a date of birth. The controls were chosen from hospitals in the study area in proportion to the number of births in each hospital in the previous year. The protocol by which the cases were identified and how the control group was selected has been described in full elsewhere. ${ }^{78}$

Parents of both cases and controls were interviewed on a wide range of topics, including child care practices and minor illnesses. Most parents were interviewed within four weeks of their infant's death. Parents of controls were interviewed within a few days of the nominated day. Obstetric records were also examined, but the data extracted were not used in this study.

During the three year period 485 SIDS deaths occurred, a rate of 3.53/1000 live births. Obstetric records were examined for 465 (96\%) of the cases and $393(81 \%)$ of their parents were interviewed. In total, 1800 controls were selected, obstetric data were available for $1762(97.9 \%)$, and the parents of 1591 $(89.4 \%)$ were interviewed.

Information on maternal smoking, the infant's sleep position at the time of death or for the nominated day (the last sleep), information 
Table 1 Distribution of SIDS deaths and controls' nominated days by day of week (public holidays)

\begin{tabular}{|c|c|c|c|c|c|c|}
\hline \multirow[b]{2}{*}{ Day of death or interview } & \multicolumn{2}{|l|}{$\begin{array}{l}\text { All cases } \\
(n=471)\end{array}$} & \multicolumn{2}{|c|}{$\begin{array}{l}\text { Cases interviewed } \\
(n=393)\end{array}$} & \multicolumn{2}{|l|}{$\begin{array}{l}\text { Controls } \\
(n=1591)\end{array}$} \\
\hline & No & $\%$ & No & $\%$ & No & $\%$ \\
\hline Monday & $53(5)$ & 11.3 & $47(3)$ & 12.0 & $210(21)$ & 12.5 \\
\hline Tuesday & $61(2)$ & 13.0 & $52(2)$ & 13.2 & $227(6)$ & 14.3 \\
\hline Wednesday & 60 & 12.7 & 52 & 13.2 & 262 & 16.5 \\
\hline Thursday & 67 & 14.2 & 51 & 13.0 & 225 & 14.1 \\
\hline Friday & $71(5)$ & 15.1 & $59(5)$ & 15.0 & 241 (3) & 15.1 \\
\hline Saturday & 64 & 13.6 & 56 & 14.2 & 210 & 13.2 \\
\hline Sunday & 95 & 20.2 & 76 & 19.3 & 216 & 13.6 \\
\hline Total for weekends & 159 & 33.8 & 132 & 33.6 & 426 & 26.8 \\
\hline \multicolumn{7}{|l|}{ Total for weekends and public } \\
\hline holidays & 171 & 36.3 & 142 & 36.1 & 456 & 28.7 \\
\hline
\end{tabular}

Number of deaths occurring or nominated days on public holidays shown in parentheses.

on bed sharing, and whether or not the infant shared a room with adults or children during the last sleep was obtained as part of the interview with parents. Questions were also asked about who was caring for the child and whether the child was at home at the time of death or the last sleep. Further questions were asked about visits by and to friends and whether or not the parents had been to a party in the last two days. Information about the mother's consumption of beer, wine, and spirits in the last month and about the occasion when most was drunk was also obtained. ${ }^{9}$ Questions about the father's consumption of alcohol were not included.

Data collected during the interview were also used to derive an illness score based on the baby check system. ${ }^{10}$ We used the following items: vomit or spill more than 30 minutes after a feed, quantity of urine less than usual, severe nappy rash in the last two weeks, and symptoms relating to the last two days, namely, long periods of wakefulness or more difficult to arouse than usual, off feeds, a change of cry as if in pain, more floppy than usual, and cough or wheeze. A report of being hot or feverish replaced that of a rectal temperature greater than $38^{\circ} \mathrm{C}$. The remaining items of the baby check system were not available. The cut off points were similar to those described in the original score and allowed infants to be classified as either having mild or no symptoms, or requiring advice from or to be seen by a medical practitioner. ${ }^{11}$

The daily minimum temperature obtained from meteorological offices in each region was used to estimate bedroom temperature. We used this in a model to predict the appropriate insulation for the lower critical temperature or the temperature below which the metabolic rate of an infant would be likely to increase. ${ }^{12}$ On this basis both cases and controls were divided into three groups: those whose bedding and clothing provided 2 tog too little insulation; those whose bedding and clothing was within 2 tog of the lower critical value; and those who had more than 2 tog extra.

For the purposes of this study weekends included all of Saturday and Sunday and the two public holidays that occur at each of Christmas, New Year, and Easter, and the Monday holidays in June (Queen's Birthday) and October (Labour Day). The holiday for Waitangi Day (in February) and ANZAC Day (in April) were also included if they occurred on a Friday or a Monday.

The odds ratio (OR) and its $95 \%$ confidence interval (CI) are presented for each risk factor for weekdays and weekends. The ORs for bed sharing and whether or not the infants shared the room with adults or other children were adjusted for race, as these practices are more common among Maori and Pacific Islanders, and for the time of the last sleep, which was known to be different for cases and controls. The use of alcohol and binge drinking were adjusted for smoking.

The estimated time of death was taken as the midpoint between the time last seen and the time found dead.

Interaction effects were particularly important in this study, because if a factor were to be more or less important at weekends than on weekdays, the respective ORs should be significantly different from each other. Logistic regression was used to compute the ORs and adjusted ORs for these effects, which were considered statistically significant if the change of deviance brought about by including a term for them in the model was more than the critical value of the $\chi^{2}$ distribution using the appropriate degrees of freedom. ${ }^{13}$ The models were adjusted for variables that have been used in other reports from this study. These include: (a) sociodemographic factors-occupation, marital status, school leaving age, and mother's age at birth of infant; (b) pregnancy factorsantenatal education class attended, month of pregnancy when mother started attending antenatal clinic, number of previous pregnancies, and mother's age at first pregnancy; (c) infant factors - sex of infant, ethnicity, birth

Table 2 No (\%) and univariate OR (95\% CI) for variables related to child care practices for weekdays, the weekend (including public holidays), and Sundays

\begin{tabular}{|c|c|c|c|c|c|c|}
\hline & \multicolumn{3}{|l|}{ Weekday } & \multicolumn{3}{|l|}{ Weekend } \\
\hline & Cases & Controls & OR $(95 \% C I)$ & Cases & Controls & OR $(95 \% C I)$ \\
\hline Prone sleeping position & $162(65.1)$ & $363(32.2)$ & $3.93(2.91$ to 5.30$)$ & $88(63.3)$ & $158(34.7)$ & $3.24(2.14$ to 4.91$)$ \\
\hline Maternal smoking & $167(66.5)$ & $358(31.5)$ & $4.31(3.19$ to 5.83$)$ & $95(66.9)$ & $152(33.3)$ & $4.04(2.66$ to 6.16$)$ \\
\hline Not breast fed in last two days ${ }^{\star}$ & $123(49.2)$ & $395(35.0)$ & $1.80(1.35$ to 2.40$)$ & $69(48.6)$ & $144(31.7)$ & $2.03(1.36$ to 3.04$)$ \\
\hline Bed sharing & $54(21.6)$ & $116(10.3)$ & $1.65(1.05$ to 2.45$)$ & $40(28.4)$ & $50(11.0)$ & $2.21(1.28$ to 3.74$)$ \\
\hline Used a dummy for last sleep & $13(5.2)$ & $119(10.5)$ & $0.47(0.25$ to 0.87$)$ & $6(4.3)$ & $46(10.1)$ & $0.40(0.15$ to 1.00$)$ \\
\hline Baby ill & $50(22.5)$ & $121(11.2)$ & $2.30(1.56$ to 3.37$)$ & $26(21.0)$ & $57(13.1)$ & $1.76(1.02$ to 3.03$)$ \\
\hline Other children in room $\dagger$ & $71(28.7)$ & $186(16.8)$ & $1.61(1.15$ to 2.26$)$ & $40(28.6)$ & $75(16.9)$ & $1.63(1.02$ to 2.61$)$ \\
\hline \multicolumn{7}{|c|}{ Insulation from bedding and clothing } \\
\hline 2 tog too little & $34(14.2)$ & $135(12.3)$ & $1.61(1.02$ to 2.53$)$ & $13(9.6)$ & $60(13.6)$ & $0.82(0.41$ to 1.64$)$ \\
\hline Within 2 tog of LCT $\ddagger$ & $60(25.1)$ & $441(40.3)$ & 1.00 & $41(30.1)$ & $155(35.3)$ & 1.00 \\
\hline More than 2 tog extra & $145(60.7)$ & $518(47.3)$ & $2.06(1.48$ to 2.85$)$ & $82(60.3)$ & $224(51.0)$ & $1.38(0.90$ to 2.12$)$ \\
\hline
\end{tabular}

* Adjusted for age. † Adjusted for time of death or interview and ethnicity. $\ddagger$ LTC $=$ lower critical temperature. 
Table 3 OR (95\% CI) for infants dying from SIDS classified by whether or not they shared a room with one or more adults and weekday or weekend and Sunday or the rest of the week

\begin{tabular}{|c|c|c|c|c|c|}
\hline & \multirow{2}{*}{$\begin{array}{l}\text { Sharing } \\
\text { room with } \\
\text { adult }\end{array}$} & \multirow[b]{2}{*}{ Cases } & \multirow[b]{2}{*}{ Controls } & \multicolumn{2}{|l|}{ OR $(95 \% C I)$} \\
\hline & & & & $\begin{array}{l}\text { Adjusted for time of death, } \\
\text { season, and ethnic origin }\end{array}$ & Multivariate* \\
\hline \multicolumn{6}{|c|}{ Weekend } \\
\hline No & No & 153 & 578 & 1.00 & 1.00 \\
\hline No & Yes & 95 & 534 & $0.41(0.30$ to 0.56$)$ & $0.21(0.14$ to 0.32$)$ \\
\hline Yes & No & 70 & 232 & $1.14(0.81$ to 1.60$)$ & $1.10(0.73$ to 1.65$)$ \\
\hline Yes & Yes & 70 & 213 & 0.740 .51 to 1.07$)$ & $0.48(0.30$ to 0.77$)$ \\
\hline \multicolumn{6}{|c|}{ Sunday } \\
\hline No & No & 188 & 695 & 1.00 & 1.00 \\
\hline No & Yes & 126 & 651 & $0.43(0.32$ to 0.57$)$ & $0.22(0.15$ to 0.32$)$ \\
\hline Yes & No & 35 & 114 & $1.10(0.72$ to 1.70$)$ & $0.89(0.52$ to 1.53$)$ \\
\hline Yes & Yes & 39 & 96 & $0.92(0.59$ to 1.45$)$ & 0.59 (0.33 to 1.07$)$ \\
\hline
\end{tabular}

* Confounding factors: (a) demographic factors - socioeconomic status (occupation) marital status, school leaving age, and mother's age at birth of infant; (b) pregnancy factors - antenatal class attended, month of pregnancy when mother started attending antenatal clinic, number of previous pregnancies, and mother's age at first pregnancy; (c) infant factors - sex of infant, ethnicity, birth weight, and gestation; and (d) postneonatal factors-region, infant's age at time of death/nominated time, season, sleeping position, maternal smoking, breast feeding, and infant sharing bed with another person.

weight, and gestation; and (d) postneonatal factors-region, infant's age, estimated time of death/nominated time, sleeping position, maternal smoking, breast feeding, and infant sharing bed with another person. The definition of these variables has been described previously. $^{78}$

The population attributable risk (PAR), which is an estimate of the proportion of cases occurring in the total population which can be explained by a particular factor, is presented for some factors. ${ }^{14}$

Ethical approval for this study was obtained from local ethics committees.

\section{Results}

Table 1 shows the number of deaths which occurred on each day of the week for all the 471 cases whose date of death was available. The one sample $\chi^{2}$ test used to compare the observed number of deaths with the expected number was significant $\left(\chi^{2}=16.19, \mathrm{df}=6, \mathrm{p}=\right.$ $0.01)$. More deaths occurred on a Sunday than on any other day. The table also shows the day of death, or the nominated day, for those whose parents were interviewed. Altogether the deaths of $142(36 \%)$ of the cases occurred at weekends or on public holidays and the parents of $456(27 \%)$ of the control infants were interviewed about a Saturday, a Sunday, or a public holiday. The OR for a death occurring at a weekend was 1.41 (95\% CI 1.12 to 1.78 ). When this was adjusted for season, to take into

Table 2 (Continued)

\begin{tabular}{lll}
\hline Sundays only & & \\
\hline Cases & Controls & OR $(95 \%$ CI $)$ \\
\hline $47(63.5)$ & $72(36.5)$ & $3.48(1.94$ to 6.28$)$ \\
$54(71.0)$ & $74(34.3)$ & $4.71(2.57$ to 8.68$)$ \\
$39(51.3)$ & $58(27.0)$ & $2.85(1.60$ to 5.08$)$ \\
$25(33.3)$ & $28(13.0)$ & $1.60(0.76$ to 3.38$)$ \\
$3(4.0)$ & $22(10.2)$ & $0.36(0.07$ to 1.28$)$ \\
$13(19.4)$ & $30(11.5)$ & $1.86(0.83$ to 4.12$)$ \\
$22(29.7)$ & $25(11.9)$ & $1.79(0.89$ to 3.60$)$ \\
$7(9.9)$ & $77(36.5)$ & $0.98(0.33$ to 2.80$)$ \\
$22(31.0)$ & $109(51.7)$ & 1.00 \\
$42(59.2)$ & & $1.35(0.72$ to 2.55$)$ \\
\hline
\end{tabular}

account the predominance of holidays in the summer, the OR was $1.44(95 \%$ CI 1.13 to 1.82). The OR was 1.46 (95\% CI 1.09 to 1.96 ) after adjusting for sociodemographic, pregnancy, infant, and postneonatal factors. The difference in time the deaths occurred was not significant: $55 \%$ of the deaths occurred between midnight and 6 am at weekends and $49 \%$ on other days. On Sundays $59 \%$ of deaths occurred in this period.

The control infants whose parents were interviewed about a weekday were compared with those whose parents were interviewed about weekends or public holidays for sociodemographic, infant, and postneonatal factors, including sharing a room with an adult and factors relating to recent activities. Except for being away from home, which occurred more often at weekends $\left(\chi^{2}=5.80, \mathrm{df}=1, \mathrm{p}=\right.$ $0.016)$, none of the differences was statistically significantly.

As the ORs for SIDS for the sociodemographic and infant factors were similar for weekdays and weekends, the results are not presented here.

The ORs for infant care practices are shown in tables 2 and 3. After adjustments were made for the sociodemographic, pregnancy, infant, and postneonatal factors, none of the interaction effects was significant, except for sharing a room with an adult (change in deviance 11.20 with $1 \mathrm{df}, \mathrm{p}<0.001)$. Table 4 shows the results in detail. Sharing a bedroom with an adult had a stronger protective effect on weekdays than it did at weekends, using weekdays and not sharing a room as the reference group. The PAR for not sharing a room with an adult was $20 \%$ on weekdays.

Table 4 shows the ORs for SIDS for factors occurring at the time of death and social activities in the last two days. The interaction effect between weekends and going to a party in the last two days was significant: change in deviance 4.72 with $1 \mathrm{df}, \mathrm{p}=0.03$ - the OR for party at the weekend being 3.19 (95\% CI 1.17 to 8.70), with not attending a party and weekdays as the reference group. Because using alcohol was strongly associated with smoking, the ORs shown in table 4 were adjusted for maternal smoking. The interaction effect between binge drinking and weekends was not significant (change in deviance $=5.02, \mathrm{df}=2$, $\mathrm{p}=0.08)$.

The OR for a death occurring on a Sunday was 1.52 (95\% CI 1.04 to 2.21 ) when adjusted for other factors. Because deaths were more common on a Sunday the analysis was repeated comparing the controls whose parents were interviewed about Sunday with those whose parents were interviewed about the rest of the week. Apart from breast feeding in the last two days, which was more common among those whose parents were interviewed about a Sunday, the differences were not statistically significant.

When the ORs for Sundays were compared with those for other days the interaction effect for ethnic group was statistically significant (change in deviance 6.42 with $2 \mathrm{df}, \mathrm{p}=0.04$ ): the adjusted OR for Maori infants dying on a 
Table 4 No (\%) and OR (95\% CI) for variables related social factors for weekdays, the weekend (including public holidays), and Sundays

\begin{tabular}{|c|c|c|c|c|c|c|}
\hline & \multicolumn{3}{|l|}{ Weekday } & \multicolumn{3}{|l|}{ Weekend } \\
\hline & Cases & Controls & $O R(95 \% C I)$ & Cases & Controls & OR $(95 \% C I)$ \\
\hline Parents not caring for child & $17(6.8)$ & $33(2.9)$ & $2.42(1.27$ to 4.57$)$ & $14(9.9)$ & $18(3.9)$ & $2.68(1.22$ to 5.85$)$ \\
\hline Away from home & $34(13.6)$ & $81(7.2)$ & $2.04(1.30$ to 3.19$)$ & $28(19.7)$ & $50(11.0)$ & $1.99(1.16$ to 3.40$)$ \\
\hline Visited by friends in last two days & $115(46.0)$ & $557(49.1)$ & $0.88(0.66$ to 1.17$)$ & $74(52.5)$ & $243(53.3)$ & $0.97(0.65$ to 1.44$)$ \\
\hline Visited friends in last two days & $109(43.4)$ & $517(45.6)$ & $0.91(0.69$ to 1.22$)$ & $67(47.2)$ & $220(48.4)$ & $0.95(0.64$ to 1.42$)$ \\
\hline Party in last two day & $6(2.4)$ & $48(4.2)$ & $0.55(0.21$ to 1.37$)$ & $13(9.2)$ & $18(4.0)$ & $2.47(1.11$ to 5.47$)$ \\
\hline Use of alcohol in last month ${ }^{\star}$ & $137(54.6)$ & $668(58.8)$ & $0.75(0.56$ to 1.00$)$ & $87(61.3)$ & $271(59.4)$ & $0.96(0.64$ to 1.43$)$ \\
\hline \multicolumn{7}{|l|}{ Binge drinking (number of glasses) ${ }^{\star}$} \\
\hline None & $95(37.8)$ & $374(32.9)$ & 1.00 & $48(33.8)$ & $155(34.0)$ & 1.00 \\
\hline $1-7$ & $113(45.0)$ & $652(57.4)$ & $0.66(0.48$ to 0.90$)$ & $55(38.7)$ & $263(57.7)$ & $0.64(0.41$ to 1.01$)$ \\
\hline 8 or more & $43(17.1)$ & $110(9.7)$ & $0.92(0.73$ to 1.15$)$ & $39(27.5)$ & $38(8.3)$ & $1.40(1.04$ to 1.87$)$ \\
\hline
\end{tabular}

^ Adjusted for smoking.

Sunday was 3.35 (95\% CI 1.75 to 6.43$)$ compared with 1.18 (95\% CI 0.79 to 1.76 ) for weekdays. Those of neither Maori nor Pacific Island descent who did not die on nor had a nominated day that was a Saturday or a weekday were the reference group. The interaction effect for the mother being married or not was also significant (change in deviance 5.86 with 1 $\mathrm{df}, \mathrm{p}=0.02$ ). The OR for the mother not being married was 3.91 (95\% CI 2.20 to 6.92 ) for Sundays compared with 1.58 (95\% CI 1.08 to 2.30) for other days using those whose mothers were married and who died on or whose nominated day was not a Sunday as the reference group. The interaction effects for the remaining demographic factors were not significant.

The ORs for the infant care practices on a Sunday presented in table 2 were similar in magnitude to those for the other periods presented in these tables. The only statistically significant interaction effect between Sunday and the rest of the week was for whether or not the infant shared a room with an adult (change in deviance 7.88 with $1 \mathrm{df}$ ) (table 3).

Table 4 gives the ORs for Sunday for social factors. Including an interaction effect between going to a party and Sunday led to a change in deviance of 2.5 with $1 \mathrm{df}$, which was not statistically significant. The change in deviance when an interaction term for binge drinking and Sunday was included in the model was 2.56 with $1 \mathrm{df}(\mathrm{p}>0.05)$.

\section{Discussion}

Our study shows that SIDS is more common at weekends, with more infants dying on a Sunday than on any other day of the week. This finding is consistent with those of an earlier New Zealand study, ${ }^{1}$ as well as those from Norway, ${ }^{4}$ Britain, ${ }^{25}$ and Australia. ${ }^{3}$ One study based on population data from England and Wales for 1979-83 suggested that deaths at the weekend were more common among infants aged from 3 months to 1 year; however, a subsequent analysis suggested that the weekend effect was only apparent in 1981 and could be attributed to deaths occurring on a particular Sunday. ${ }^{15}$ No effect for weekends was evident in data collected for England and Wales from 1984 to 1986, nor from New South Wales, Australia from 1981 to $1985 .{ }^{15}$ Another study showed that deaths were more common in Tasmania on Mondays in the period 1970-6. ${ }^{16}$

As the earlier New Zealand study ${ }^{1}$ showed that SIDS was more common at weekends and on public holidays, the first series of analyses compared the whole weekend-that is, all of Saturday and Sunday and public holidayswith the rest of the week. We excluded local public holidays as they occur on various days. Other studies have found an increase in SIDS on Sundays, ${ }^{2}$ so this was addressed in the second series of analyses.

As the controls were a representative sample of all live births in the study region, bias should not be present. Elsewhere we have argued that in this study the completion rates for examination of obstetric records were high for both cases and controls, suggesting that selection bias was not present in this sample. ${ }^{7}$ Recall bias can also be a problem in retrospective studies, and again we have argued that this was not a major problem in case-control studies for SIDS. ${ }^{7}$

If the effect for weekends is important, it must be an effect modifier for other risk factors for SIDS, as it is unlikely that weekends per se are causally related to SIDS. Our study has shown that the effects of infant and sociodemographic factors were similar for infants dying during the week and infants dying at the weekends. It has also shown that the interaction effects between weekends and the four major modifiable risk factors-prone sleep position, maternal smoking, breast feeding, and bed sharing -identified earlier were not significant. ${ }^{78}$ There was, however, a significant interaction effect for sharing a room with an adult, which we have shown is protective. ${ }^{17}$ The study found that sharing a room with an adult was less protective at the weekend than it was on weekdays. A consistent result was found when Sundays were compared with other days. This could be because parents are more relaxed, away from the pressures of work, and sleep more deeply, making them less likely to respond to their infant's needs.

As part of the interview parents were asked about who had cared for their infant and whether the child was away from home at the time of death or the nominated time. Both these were risk factors for SIDS and had effects of similar magnitude for both weekdays and at weekends. Questions about parents' activities in the last two days showed that the effect of visiting or being visited by friends was similar. Going to a party was a risk factor at weekends, but not during the week. This finding, although it applied to relatively few, suggests that consuming alcohol may have a role. More than 
Table 4 (Continued)

\begin{tabular}{lll}
\hline \multicolumn{1}{l}{ Sundays } & & \\
\hline Cases & Controls & OR (95\% CI) \\
\hline $18(24.0)$ & $32(14.8)$ & $1.82(0.90$ to 3.64$)$ \\
$17(22.4)$ & $23(10.7)$ & $2.38(1.14$ to 5.00$)$ \\
$43(57.3)$ & $124(57.4)$ & $1.00(0.57$ to 1.76$)$ \\
$37(48.7)$ & $110(50.9)$ & $4.07(1.32$ to 1.59$)$ \\
$9(12.0)$ & $7(3.2)$ & $0.88(0.50$ to 1.57$)$ \\
$46(60.5)$ & $137(63.4)$ & 1.00 \\
$27(35.5)$ & $70(24.0)$ & $0.56(0.29$ to 1.07$)$ \\
$27(35.5)$ & $126(43.2)$ & $2.85(1.26$ to 4.68$)$ \\
$22(30.0)$ & $20(6.9)$ & \\
\hline
\end{tabular}

half the mothers of both cases and controls had used alcohol in the last month, but binge drinking was more common among those whose infants died at weekends. However, although alcohol has been implicated in case series, case-control studies have not shown an increased risk. ${ }^{9}$ When these risk factors were considered for just Sunday, rather than weekends as a whole, the magnitude of the ORs was similar apart from those for going to a party and binge drinking, where they were higher. The interaction effect between them and other days was not significant, possibly the consequence of decreased statistical power.

The main finding relating to Sunday was the increased risk of SIDS among Maori infants and infants of unmarried mothers. Although it is possible to speculate that this represents deficiencies in maternal care, other findings from our study do not support this.

The results of our study should not detract from the importance of prone sleep position as a risk factor for SIDS. However, they suggest that other factors may be involved, especially at weekends. It is possible that the incidence of SIDS might be reduced further if these were identified.
The study was funded by the Health Research Council of New Zealand (HRCNZ) and the Hawkes Bay Medical Research Foundation. The authors thank the research interviewers who undertook interviews and the various Plunket Society branches who paid their travelling expenses. Mrs Everard coordinated the study, $\mathrm{Mr} \mathrm{M}$ Clements organised the data. Mrs Everard, $\mathrm{Mr}$ Thompson, Mr Stewart, and Mrs Williams were funded by HRCNZ.

1 Mitchell EA, Stewart AW. Deaths from sudden infant death syndrome on public holidays and weekends. Med $\mathcal{F}$ Aust 1988;18:861-3.

2 Emery JL. Epidemiology of 'sudden, unexpected, or rapid' deaths in children. BMF 1959;ii:925-8.

3 Beal S. Sudden infant death syndrome. Med F Aust 1972;ii: 1223-9

4 Kaada B, Siversten E. Sudden infant death syndrome during weekends and holidays in Norway in 1967-1985. Scand F Soc Med 1990;18:17-23.

5 Brooke H, Gibson A, Tappin D, Brown H. Case-control study of sudden infant death syndrome in Scotland, 1992-5. BMF 1997;314:1516-20.

6 Murphy MFG, Campbell MJ, Jones DR. Increased risk of sudden infant death syndrome in older infants at weekends. BMF 1986;293:364-5.

7 Mitchell EA, Scragg R, Stewart AW, et al. Results from the first year of the New Zealand cot death study. $N Z M e d \mathcal{F}$ 1991;104:71-6.

8 Mitchell EA, Taylor BJ, Ford RPK, et al. Four modifiable and other major risk factors for cot death: the New Zealand and other major risk factors for cot death: the New
study. F Paediatr Child Health 1992;28(suppl):53-8.

9 Scragg R, Mitchell EA, Taylor BJ, et al. Bed sharing, smoking, and alcohol in the sudden infant death syndrome. BMF 1993;307:1312-8

10 Morley CJ, Thornton AJ, Cole TJ, Hewson PH, Fowler MA. Baby check: a scoring system to grade the severity of illness in babies under 6 months old. Arch Dis Child 1991; 66:100-5.

11 Taylor BJ, Williams SM, Mitchell EA, Ford RPK. Symptoms of illness and reactivity of infants who die of SIDS compared with community controls. F Paediatr Child Health 1996;32:316-22

12 Williams SM, Taylor BJ, Mitchell EA. Sudden infant death syndrome: insulation from bedding and clothing and its syndrome: insulation from bedding and cloth

13 Hosmer DW, Lemeshow S. Applied logistic regression. New York: WW, Lem

14 Breslow NE, Day NE. Statistical methods in cancer research. Lyon: International Agency for Research on Cancer, 1980.

15 Campbell MJ. Time series regression for counts: an investigation into the relationship between sudden infant death syndrome and environmental temperature. Fournal of the Royal Statistical Society Series A 1994;157:191-208.

16 McGlashan ND, Grice AC. Sudden infant deaths and seasonality in Tasmania, 1970-1976. Soc Sci Med 1983;17: 885-8.

17 Scragg RKR, Mitchell AE, Stewart AW, et al. Infant room-sharing and prone sleep position in sudden infant death syndrome. Lancet 1996;347:7-12. 